\title{
UM PLEITO POR MEMÓRIA E PERMANÊNCIA. O CASO DOS MORADORES DAS MARGENS DA BR 040
}

\author{
A PLEA FOR MEMORY AND PERMANENCE. THE CASE OF RESIDENTS ON THE BR \\ o40 MARGINS
}

\author{
Jonatan da Silva Ribeiro ${ }^{1}$
}

RESUMO: Moradores das margens da BR-o4o na altura que liga o município de Petrópolis (Rio de Janeiro) ao município de Juiz de Fora (Minas Gerais), recebem da CONCER, agência queadministra a rodovia, intimações com aviso de despejos, já que segundo a concessionária, eles habitam nas áreas de faixa de domínio da rodovia. Esses moradores unem-se e formam grupos que vão para as ruas reivindicar seus direitos de moradia e memória.

Palavras-chave: Memória. Movimentos Sociais. Moradia.

SUMMARY: Residents on the banks of the BR-040 at the time that links the municipality of Petrópolis (Rio de Janeiro) to the municipality of Juiz de Fora (Minas Gerais), receive subpoenas with eviction notices from CONCER, the agency that manages the highway, as they say. the concessionaire, they live in the highway's right-of-way areas. These residents unite and form groups that take to the streets to claim their housing and memory rights.

Keywords: Memory. Social Movements. Housing.

\section{INTRODUÇÃO}

Levando em consideração os aspectos da teoria da memória e os sentidos que são atribuídos a esse conceito, esse trabalho como parte de uma pesquisa pessoal se propõe a analisar pelo viés do complexo conceito de movimentos sociais e dos estudos da memória o fenômeno que é desencadeado no trecho da rodovia BR-o4o que liga Petrópolis - RJ à Juiz de Fora - MG.

De acordo com Mutzenberg (20II) a apropriação da noção de cidadania pelos movimentos sociais teria sido um instrumento fundamental, os levando a um protagonismo de uma nova cultura política. É importante ressaltar que o crescente recurso de "bloqueio de rua" com o objetivo de dar visibilidade a demandas locais, tem chamado muito atenção nos últimos anos, o autor conclui que a multiplicidade de manifestações coletivas e a diversidade de suas características impossibilita uma

\footnotetext{
${ }^{1}$ Mestrando em Memória Social pelo Programa de Pós-graduação da Universidade Federal do Estado do Rio de Janeiro. E-mail: jonatan3ı@gmail.com.
} 
definição geral do conceito de movimentos sociais, sendo necessário considerar que os atores sociais têm um papel ativo na construção do significado de movimento social. (MUTZENBERG, 20II).

Alain Touraine define movimento social como "a ação conflitante de agentes de classes sociais lutando pelo controle do sistema de ação histórica.” (1977:336). Assim os movimentos sociais se definem pelo "confronto de interesses opostos para controlar forças de desenvolvimento e do campo da experiência histórica de uma sociedade". (1977:344). Nesse sentido, o autor defende que os movimentos sociais devem ter a função de mediadores entre sujeito e o Estado, os movimentos sociais têm o papel de desenvolverem indivíduos livres e autônomos, por um lado e construírem as mediações necessárias entre Estado e os indivíduos por outro.(PICOLOTTO, 2007).

Esses grupos vão para as ruas lutar para derrubar as ordens judiciais de demolição de seus imóveis e assim mostram como tem em seus rescpectivos espaços memórias e um vínculo afetivo muito forte, superando a vaga ideia de progresso.

\section{CONTEXTUALIZAÇÃO TEÓRICA}

A memória é uma operação coletiva dos acontecimentos e das interpretações do passado que se quer salvaguardar. A referência ao passado serve para manter a coesão dos grupos e das instituições que compõe uma sociedade. Os lugares de memória nascem e vivem do sentimento que não há memória espontânea, que existe a necessidade de criar arquivos, a memória pendura-se em lugares. (POLLAK, 1989; NORA, 1993).

A memória opera a partir de um processo seletivo e pode se tornar uma arma política para as vítimas de guerras e genocídios, em que o esquecimento estabeleceu sua hegemonia. A memória individual revela apenas a complexidade das interações sociais vivenciadas por cada um. Halbwachs mostra que a memória individual não pode ser distanciada das memórias coletivas, a memória é constituída por indivíduos em interação, por grupos sociais, sendo as lembranças individuais resultado desse processo. (ARAÚJO; SANTOS, 2007).

Contribuindo para as reflexões deste projeto, podemos citar Halbwachs (2004), pois este desenvolveu a categoria de memória coletiva, que tem por definição uma representação coletiva de grupos sociais, com a finalidade de mantê-los coesos e unidos. Nesse sentido, as memórias individuais somente fariam sentido dentro de quadros sociais de memória mais amplos. Essa memória coletiva, porém, só poderia ser apreendida e reproduzida mediante as práticas sociais dos grupos, ou seja, empiricamente. Assim, a preservação da memória dos grupos sociais é reivindicada como o fundamento da preservação dos próprios grupos sociais. Sem a preservação e valorização da 
memória coletiva, a identidade dos grupos e sua coesão interna estariam ameaçadas. Com a memória se entrelaça o processo de construção das identidades dos grupos sociais e, por conseguinte, dos sujeitos. Respeitar o direito dos indivíduos de se lembrar do seu passado é uma maneira de assegurar a preservação e o fortalecimento de suas identidades culturais, constituindo sua subjetividade (SANTOS, 2007).

No sentido mais público do patrimônio, os lugares têm a força de se impor como espaços de apoio ou comemoração de acontecimentos que o indivíduo pode ou não ter vivido. Esses lugares acabam funcionando como um suporte de acontecimentos experimentados pelo grupo ou coletividade a qual se possa pertencer. Lugares distantes ou fora do espaço-tempo do sujeito, também possibilitam a construção de lugares importantes para a memória de um grupo. É interessante compreender que uma noção fundamental de referência da memória de um grupo acaba estando pautada na durabilidade da materialidade desses espaços. (HOFFMAN. p-64.2015).

Michael Pollak traz a noção de memórias subterrâneas que seriam, memórias "clandestinas" que são transmitidas de uma geração para outra, geralmente por meio da oralidade, que sobrevivem por anos e aguardam o momento certo para serem reveladas. As memórias subterrâneas não estão fadadas ao esquecimento, ficam silenciadas e se caracterizam como uma forma de resistência e vão contra o discurso de uma memória oficial e que domina. (POLLAK, 1989).

Nesse contexto de disputas entre uma memória oficial, predominante na Concer, ANTT e órgãos de Estado de um país que domina seu território e mostrar ter propriedade sobre ele quando necessário, não é exagero trazer a discussão da pesquisa o conceito de História a Contrapelo de Walter Benjamin (1940), pois percebe-se de forma clara uma negação do Estado a respeito das memórias vividas por essas famílias em seu aspecto coletivo e individual que Michel Pollak descreve com maestria.

Michel Pollak (1989) traz importantes inovações para a abordagem sociológica da memória, mas não rompe com a obra de Halbwachs e é influenciado de muitas maneiras pelo sociólogo francês, as definições de memória de ambos os autores concordam em diversos pontos.

Em linhas gerais tanto Halbwachs como Pollak apontam a memória como um fenômeno coletivo, definindo-a como construção social. Por ser uma construção social a memória envolve um processo de escolha, sendo parcial e seletiva, ambos definem a memória como uma construção do passado realizada no presente, ela seria variável e também múltipla, pois cada grupo cultiva um conjunto particular de recordações. 
Pollak e Halbwachs apontam o papel fundamental da memória para a criação do sentimento de identidade, existem diferenças cruciais entre os autores, para Pollak o indivíduo também tem suas lembranças, o que contraria a visão de Halbwachs, para quem o social se define em oposição ao individual. Para Pollak o indivíduo possui a capacidade de acessar e formar memórias, participando ativamente da reconstrução das recordações dos grupos. (HALBWACHS, 2004, POLLAK, 1989).

Para Pollak as memórias, sejam individuais ou coletivas incluem sempre três elementos: acontecimentos - pessoas - lugares. A constituição de memórias envolve não só experiências vividas diretamente, mas também experiências herdadas, aprendidas, transmitidas aos indivíduos pelos grupos através do processo de socialização. Pollak se aproximando de Halbwachs defende a importância da memória para a afirmação do sentimento de identidade de indivíduos e grupos.(HALBWACHS, 2004, POLLAK, 1989).

A partir da Escola dos Annales, fundada em 1929 surge o conceito da nova HistóriaProblema, em que pese seus fundadores defendiam o uso de hipóteses explicitadas pelo historiador, hipóteses essas abertas que tinham a função de um fio condutor para a pesquisa. Segundo esses intelectuais o pesquisador constrói seu material, documentos em séries inteligíveis, que ele integra ao seu quadro teórico, prévio e adapta a sua pesquisa. "Nada caminha por si mesmo. Nada é dado. Tudo é construído." (DOSSE, 1997).

Quando esses grupos se unem na luta por suas ideias e procuram proteger não somente seu patrimônio material, mas por trás toda uma memória estabelecida com o local, formam como descreve Javier Lifschitz, grupos de memória, com vínculos sociais. Tais grupos na visão de Lifschitz possuem diferentes pontos de vista, sobre o passado, surgem e podem desaparecer sempre de forma espontânea. Nesse sentido confirma-se que a memória não é uma gestald e que gera campos de atração. $O$ conceito de memória política defendida pelo autor mostra que ela tem o papel de confrontar a realidade jurídica, cultural e política, porque se trata de narrativas e práticas que somente adquirem potência quando ingressam na esfera pública. (LIFSCHITZ, 2016).

\section{METODOLOGIA}

Cellard (2008,p.296, apud ALMEIDA; GUINDANI; SÁ-SILVA, 2009,p.7) mostra que ao privilegiar uma abordagem mais ampla de documento, a Escola de Annales, uma das linhas teóricas da História, estende para além do texto dos arquivos oficiais, a noção de documento. Desta forma, segundo o autor anteriormente citado, o conceito de documento passa a ser: "tudo o que é vestígio 
do passado, tudo o que serve de testemunho, é considerado como documento ou 'fonte"' (CELLARD, 2008, p. 296). E mais: "pode tratar-se de textos escritos, mas também de documentos de natureza iconográfica e cinematográfica, ou de qualquer outro tipo de testemunho registrado, objetos do cotidiano, elementos folclóricos, etc" (p. 297).

Os dados coletados na imprensa municipal produzidos tanto pelos movimentos sociais como pelo proprietário do imóvel Renato Noronha, o Relatório da Comissão Municipal da Verdade, como documento oficial de Estado, o acervo de um dos principais movimentos sociais o (CPL), as reportagens da imprensa televisava como fontes testemunhais (FERRO, 1993), foram imprescindíveis para a elaboração desse trabalho.

Oliveira (2007,p.69, apud ALMEIDA; GUINDANI; SÁ-SILVA, 2009,p.6) faz uma importante distinção entre pesquisa bibliográfica e pesquisa documental. Para essa autora a pesquisa bibliográfica é uma modalidade de estudo e análise de documentos de domínio científicos tais como livros, periódicos, enciclopédias, ensaios críticos, dicionários e artigos científicos. Como característica diferenciadora ela pontua que é um tipo de "estudo direto em fontes científicas, sem precisar recorrer diretamente aos fatos/fenômenos da realidade empírica" (p.69). Argumenta que a principal finalidade da pesquisa bibliográfica é proporcionar aos pesquisadores o contato direto com obras, artigos ou documentos que tratem do tema em estudo: "o mais importante para quem faz opção pela pesquisa bibliográfica é ter a certeza de que as fontes a serem pesquisadas já são reconhecidamente do domínio científico" (p. 69). Ela se posiciona sobre a pesquisa documental: "a documental caracteriza-se pela busca de informações em documentos que não receberam nenhum tratamento científico, como relatórios, reportagens de jornais, revistas, cartas, filmes, gravações, fotografias, entre outras matérias de divulgação" (p.69).

\section{RESULTADOS}

A BR-04o é uma importante rodovia que liga o Rio de Janeiro a Belo Horizonte. O trecho Rio e Petrópolis foi inaugurado em 25 de agosto de 1928, pelo presidente da época Washington Luís. Um grande avanço para o capitalismo brasileiro, a BR-o4o trouxe expectativas e progresso, em seu período de construção a frota de automóveis e veículos se resumia a menos de 20 mil em território nacional. A construção da rodovia foi um grande desafio para a engenharia naquele contexto, com seus seis viadutos. ${ }^{2}$

\footnotetext{
${ }^{2}$ Companhia de Concessão Rodoviária Juiz de Fora - Rio (ANTT). Acesso em 18/03/2021.
} 
Em 1931, a BR-04o transformou-se na primeira rodovia asfaltada do país e na subida da Serra, foram instaladas as primeiras placas de concreto. Na década de 1950, o governo federal inaugurou a Estrada do Contorno (atual pista de descida) que liga Itaipava a Xerém, em Duque de Caxias. No ano de 1980, foi inaugurada a BRo4o, substituindo a importante Estrada União Indústria ${ }^{3}$, construída no século XIX pelo imperador Dom Pedro II. ${ }^{4}$

A rodovia BR-o4o tem seu ponto inicial em Brasília (DF) e seu ponto final no Rio de Janeiro, mais especificamente na Rodoviária Novo Rio. Seu percurso passa pelo Distrito Federal, estados de Goiás, Minas Gerais e Rio de Janeiro, assumindo o papel de principal ligação ferroviária entre esses estados.

Em setembro de 2009, o trecho compreendido entre Brasília (DF) e Petrópolis (RJ) foi nomeado com o título de Rodovia Presidente Juscelino Kubitschek, por meio de uma sanção presidencial da Lei Federal $N^{\circ}$ 12.028/2009 pelo então presidente Luís Inácio Lula da Silva. ${ }^{5}$

O trecho da BR-o4o que liga Petrópolis e o Rio de Janeiro, homenageou o ex-presidente Washington Luís, que ficou conhecido por construir muitas rodovias em seu mandato (de 1926 até 1930), incluindo esse trecho da rodovia, que fora batizado com seu nome. ${ }^{6}$

O então presidente da República, Washington Luís usava diante da sociedade brasileira o bordão: “Governar é construir estradas”, era o contexto de um país ainda extremamente agrário com uma frota reduzida de automóveis. A estrada Rio-Petrópolis teve um certo peso e privilégio, sendo prioridade na pauta do governo, por conta de duras críticas feitas pela imprensa, apontando o abandono do caminho que levava a Cidade Imperial (Petrópolis).

Possuindo oito metros de largura de plataforma, a Rio-Petrópolis era inaugurada pelo presidente Washington Luís, em 25 de agosto de 1928. Dois dias depois da inauguração numerosos caminhões assustavam os usuários da pista, devido seus trechos com temerosos perigos de altura. A antiga Rio-Petrópolis por muito tempo levou o elogio de melhor rodovia da América do Sul. ${ }^{7}$

\footnotetext{
${ }^{3}$ A Estrada União Indústria fora construída em 23 de junho de I86I, ligando as cidades de Petrópolis (RJ) e Juiz de Fora (MG), foi a primeira rodovia macadamizada da América Latina, transformou Juiz de Fora em uma importante rota entre os dois Estados.

${ }^{4}$ Companhia de Concessão Rodoviária Juiz de Fora - Rio (ANTT). Acesso em 18/03/2021.

${ }^{5}$ Página da VIAo4o (Trecho Brasília-Juiz de Fora):http://www.viao4o.invepar.com.br/Páginas do Ministério dos Transportes]. Acesso em 16.03 de 2021. às 13:20.

${ }^{6}$ Companhia de Concessão Rodoviária Juiz de Fora - Rio (ANTT). Acesso em i8/03/2021.

${ }^{7}$ Companhia de Concessão Rodoviária Juiz de Fora - Rio (ANTT). Acesso em i8/03/2021.
} 
O trecho Petrópolis-Juiz de Fora foi concluído em is de junho de 1980 e substituiu a Estrada União Indústria, a primeira rodovia do país. De Petrópolis a Juiz de Fora a pista corta sete municípios em um percurso de 138 quilômetros, com volume de tráfico de sete mil veículos por dia.

No dia primeiro de março de 1996, o trecho entre Rio de Janeiro e Juiz de Fora foi privatizado, pelo prazo de 25 anos, concedido a administradora Concer. Com três praças de pedágio $\mathrm{km} 104$ (Duque de Caxias), km45 (Areal) e em Minas Gerais km8ı4 (Simão Pereira). ${ }^{8}$

A Companhia de Concessão Rodoviária Juiz de Fora-Rio de Janeiro, popularmente conhecida como Concer, é uma concessionária que tem por objetivo a administração de rodovias, fundada em 1995, ficou responsável pela gestão de i8o quilômetros, no trecho compreendido entre Juiz de Fora e Rio de Janeiro. A concessionária assumiu a rodovia a partir de I de março de 1996, com o fim do DNER ${ }^{9} \mathrm{em}$ 3I de outubro de 1995. A responsabilidade pela administração, manutenção, recuperação e outras melhorias na BR-04o (RJ/MG) ficou a cargo da Concer pelos próximos 25 anos. $^{10}$

A Nova Subida da Serra (NSS) fará parte do trecho administrado pela Concer, a empreitada tem por missão construir uma pista com traçado mais seguro e ampliar sua capacidade de fluxo em substituição a atual subida da serra, que já está em estágio de saturagem e defasagem, graças ao aumento da demanda de veículos leves e pesados no percurso da estrada. ${ }^{\text {II }}$

O novo trecho trará imensos benefícios aos usuários e ao meio ambiente, pois será capaz de reduzir o consumo de combustível, terá traçados menos sinuosos, acostamento etc. No trecho final será construído um túnel, com aproximadamente 5.000 quilômetros ${ }^{12}$, uma saída encontrada pela Concer para amenizar os impactos nos trechos com predominância da Mata Atlântica. ${ }^{13}$

A ANTT ${ }^{14}$ autorizou a obra apenas em 2013, após longas discussões, desde 1995 sobre projetos de ressarcimento, em que a União por meio da ANTT devolveria o dinheiro a Concer, investido nas obras.

\footnotetext{
8 Tarifas de Pedágios. Acesso em 20/03/2021.

${ }^{9}$ Departamento Nacional de Estradas de Rodagem, órgão federal vinculado ao Ministério dos Transportes, coordenava e gerenciava todo o sistema rodoviário brasileiro. (1937-200I).

10 «ABCR-Informações sobre a Concer».Acesso em 17/03/2021.

11 «PROJETO DA NOVA SUBIDA DA SERRA VAI SUBSTITUIR RIO-PETRÓPOLIS». Acesso em $15 / 02 / 2021$

${ }^{12}$ «Serra de Petrópolis terá túnel de 4,6 quilômetros». Acesso em 20/03/2021.

${ }^{13}$ Nova Subida de Serra. Acesso em 02/02/2021.

${ }^{14}$ Agência Nacional de Transportes Terrestres, regula atividades da infraestrutura ferroviária do Brasil, vinculada ao Ministério da Infraestrutura.
} 
Os moradores que ocupam cerca de 300 casas nas áreas de faixas de domínio da União, consecutivamente de posse da BR-040, passaram a sofrer ameaças de despejo, em ações judiciais movidas pela Concer. A concessionária por meio desses processos passa a exigir a demolição dessas casas, em depoimentos prestados a Tribuna de Petrópolis, é possível perceber que muitas dessas casas, já existiam quando foram iniciadas as obras de construção da rodovia. ${ }^{15}$

O Centro de Defesa dos Direitos Humanos de Petrópolis (CDDH), já acompanha a luta há um bom tempo e segundo eles esse pleito dos moradores já dura mais de 12 anos. Já existem 44 mandados de demolição, e o CDDH busca dar apoio a esses moradores e assume a luta em seu campo político e burocrático. A prefeitura busca a redução da faixa de domínio da rodovia, para conter maiores demolições e famílias atingidas. (TRIBUNA DE PETRÓPOLIS, 2019).

A advogada do CDDH destaca em entrevista prestada a imprensa local, que essas famílias atingidas pelos processos de demolição da Concer, são em sua maioria famílias vulneráveis. A advogada mostra que em uma das casas mora um casal de idosos que luta contra o mal de Alzheimer, em outra uma senhora de 82 anos que reside com suas duas filhas e uma família composta por pai, mãe e três filhos pequenos, sendo muito importante de acordo com a advogada prestar socorro e apoio a essas famílias. (TRIBUNA DE PETRÓPOLIS, 2019).

Nesse contexto algumas casas já estavam com data marcada para serem demolidas e uma chegou a ser derrubada por ordem judicial. A balconista Carla de 26 anos, que vive às margens da BR-o4o desde que era bebê, afirma em entrevista prestada ao jornal impresso da região, que só quer paz e ficar em sua casa sem ser surpreendida com a notícia de que seu imóvel será demolido. Carla vive com sua mãe de 62 anos e sua irmã de 23, quinze dias antes de ser entrevistada havia abandonado seu lar, ao ser notificada por um oficial de justiça de que aquela casa estava condenada a demolição. A Prefeitura de Petrópolis conseguiu uma liminar para adiar a demolição. Sua mãe passou mal com a situação, tendo sua mudança (retira de pertences do imóvel) sido acompanhada por fiscais. $\mathrm{Na}$ comunidade do Gavião no $\mathrm{km} 74$ a casa de um pedreiro foi demolida. O pedreiro Stevens Ferreira Braga de 43 anos foi forçado a mudar-se com sua família para a casa da sogra.

Consultando a Tribuna de Petrópolis é possível conhecer vários atos promovidos por moradores das localidades às margens da BR-040, como o caso em que 50 pessoas impediram a demolição de um imóvel na altura de Barra Mansa do Km46,5 em Petrópolis, junto com esse protesto

\footnotetext{
${ }^{15}$ Tribuna de Petrópolis, 2019.
} 
foram impedidas 17 demolições, porém, isso não quis dizer que a luta acabou, foi apenas um tempo ganho na causa.

Sueli é um outro caso conhecido na disputa, mora há is anos na região conhecida como Mondezir, além de seu lar, outros is estão edificados nas redondezas e também foram marcados para ser derrubados.

O teólogo e escritor Leonardo Boff abraçou a luta dos moradores, inclusive em um dos atos ficou sentado em uma cadeira em frente à casa de Sueli e disse: "Se quiserem derrubar a casa podem passar por cima de mim”. Em outubro de 2019 a Prefeitura de Petrópolis conseguiu suspender a demolição de pelo menos II imóveis junto a $\mathrm{I}^{\circ}$ Vara Federal e busca na ANTT uma ampliação da faixa de domínio da rodovia. (TRIBUNA DE PETRÓPOLIS, 2019).

Nesse embate vez por outra a Concer tem garantido o direito de suspensão provisória de demolição das casas, em uma luta que tem envolvido a Prefeitura de Petrópolis, o CDDH, o Judiciário Municipal, a ANTT, o Ministério Público Federal, o ITERJ (Instituto de Terras e Cartografia do Estado do Rio de Janeiro, a APA Petrópolis e as famílias envolvidas, cada qual com suas disputas, discursos, narrativas e memórias sensíveis. (HALBWACHS 2004).

Mesmo diante de suspensões de demolição a Concer não exita em proteger sua faixa de domínio. Nesse contexto a Prefeitura de Petrópolis formou um grupo chamado de Secretarias de Obras, Habitação e Regulamentação Fundiária e Assistência Social, usando o argumento de que essas famílias já estão consolidadas neles locais e possuem direito a sua moradia.

Moradores da BR-040, acompanhados de movimentos sociais e do CDDH realizaram uma manifestação contra as demolições, no Km7ı da rodovia, onde uma casa seria derrubada. A Concer afirma em entrevista a Tribuna de Petrópolis, apenas ser cumpridora de ordens judiciais, a ANTT diz não ter poder sobre a determinação de demolição ou ajuizamento de açães e lembra que o projeto da rodovia busca a segurança de todos.

Mais de cinquenta pessoas ocuparam a frente da Prefeitura de Petrópolis, pedindo apoio do governo municipal na questão das demolições. Segundo a advogada do $\mathrm{CDDH}$, diversas tentativas junto a ANTT para suspender as demolições foram recusadas. (TRIBUNA DE PETRÓPOLIS, 2019).

\section{CONCLUSÕES}

De acordo com Beatriz Sarlo o passado é sempre conflituoso, estando em constante concorrência a memória e a História, nem sempre a História consegue acreditar na memória e a 
memória desconfia de uma reconstituição que não coloque em seu centro os direitos da lembrança. Nesse sentindo a lembrança não permite ser deslocada, pelo contrário ela é constituída por uma decorrente perseguição, por nunca estar completa. (SARLO, 2007).

A lembrança insiste porque de certa maneira é soberana e incontrolável, precisando sempre do presente, que é o seu tempo próprio para lembrar. O tempo passado, de acordo com Sarlo não pode ser eliminado e é um perseguidor capaz de escravizar ou libertar. (SARLO, 2007).

A memória não está pautada somente no passado, mas também no futuro, sendo sua compreensão como um dispositivo, fonte de nossa subjetividade, estudar o contemporâneo também é um campo da memória social. Compreender a memória como relação, como rede, vem sendo objeto de estudo na atualidade. (DODEBEI, GONDAR, FARIAS, 2016).

A memória se produz em uma relação com a alteridade (diferença), só há memória quando existe a experiência com o diferente, sendo uma atividade dinâmica o ato de lembrar e o ato de esquecer. Nessa categoria a memória se põe como plástica, maleável, sujeita a interferências, a memória é pensamento, reflexão, imaginação, não é espontânea sendo preciso uma vontade de memória. Existem "suportes de memória" de várias modalidades, materiais e imateriais, sendo o patrimônio como um lugar de referência por onde opera a memória social, dessa forma é possível afirmar que existem referências materiais e imateriais que mantêm uma relação estreita com a memória social. (ABREU, 2016).

Em épocas de regimes totalitários, uma prática comum é a da destruição de arquivos, documentos, monumentos, prédios e vestígios que possam relembrar os horrores dos acontecimentos de natureza traumática. De acordo com Farias e Pinto, o cerne da discussão sobre a memória social traumática está em pensar na possibilidade de construção de memória em uma situação antagônica na qual, em um polo parece haver o triunfo do esquecimento, escondendo as atrocidades humanas, e de um outro polo o surgimento de mobilizações combatentes na intenção de produzir uma escritura da situação vivida. (FARIAS, PINTO, 2016).

\section{REFERÊNCIAS}

ADORNO, T. W. O que significa elaborar o passado. In: ADORNO, T. W. Educação e emancipação. Rio de Janeiro: Paz e Terra, 1995b. p. 29-49.

ARAÚJO, Maria Paula Nascimento. SANTOS, Myriam Sepúlveda. História, Memória e esquecimento: Implicações políticas. Revista Crítica de Ciências Sociais. 79. Dezembro.2007. p.95-II. 
BENJAMIN, Walter. Sobre o conceito da História. In: Magia e técnica, arte e política: ensaios sobre literatura e história da cultura. Trad. Sérgio Paulo Rouanet, São Paulo: Brasiliense, 1985. p. 222232. (Obras escolhidas, v. I)

CELLARD, A. (2008). A análise documental. In: POUPART, J. (Ed.). A pesquisa qualitativa: enfoques epistemológicos e metodológicos. Petrópolis: Vozes.

DODEBEI, V; FARIAS, F.R; GONDAR, J. Por que Memória Social? Revista Morfheus. Edição Especial, v.9, n-15, p.7-318, 2016.

HALBWACHS, Maurice. A memória coletiva. São Paulo: Centauro, 2004

HOFFAMN, Felipe Heleotério. O espaço construído na produção de lugares de memória. Reflexões sobre museus e lugares de memória do trauma, estudo de casos em Belo Horizonte. 2015.

LE GOFF, J. 1994. História e memória. 3. ed., Campinas, SP: Ed. Unicamp. NORA, P. 1993. "Entre memória e história: a problemática dos lugares”. Projeto História, n. 10, p. 7-28.

PADRÓS, Enrique; et all. A Ditadura de Segurança Nacional no Rio Grande do Sul 1964- 1985: História e Memória. Conexão repressiva e Operação Condor. vol. $3.2^{\circ}$ ed. Ver. e Ampl. Porto Alegre: Corag, 2oro.

POLLAK, Michael. A gestão do indizível; WebMosaica Revista do Instituto Judaico Marc Chagall v.2.n.I, p.9-49, 2oro. POLLAK, Michael. "Memória, Esquecimento e Silêncio". In: Estudos Históricos, Rio de Janeiro, CPDOC/FGV, vol. 2, nํㅜㅇ, 1989, 3-15.

OLIVEIRA, M. (2007). Como fazer pesquisa qualitativa. Petrópolis: Vozes 